\title{
Mechanisms of worsening gas exchange during acute exacerbations of chronic obstructive pulmonary disease
}

\author{
J.A. Barberà, J. Roca, A. Ferrer, M.A. Félez, O. Díaz*, \\ N. Roger, R. Rodriguez-Roisin
}

Mechanisms of worsening gas exchange during acute exacerbations of chronic obstructive pulmonary disease. J.A. Barberà, J. Roca, A. Ferrer, M.A. Félez, O. Díaz, N. Roger, R. Rodriguez-Roisin. CERS Journals Ltd 1997.

ABSTRACT: This study was undertaken to investigate the mechanisms that determine abnormal gas exchange during acute exacerbations of chronic obstructive pulmonary disease (COPD).

Thirteen COPD patients, hospitalized because of an exacerbation, were studied after admission and $38 \pm 10( \pm \mathrm{sD})$ days after discharge, once they were clinically stable. Measurements included forced spirometry, arterial blood gas values, minute ventilation $\left(V^{\prime} \mathrm{E}\right)$, cardiac output $\left(\bar{Q}^{\prime}\right)$, oxygen consumption $\left(V^{\prime} \mathrm{O}_{2}\right)$, and ventilation/perfusion $\left(V^{\prime} \mathrm{A} / Q^{\prime}\right)$ relationships, assessed by the inert gas technique.

Exacerbations were characterized by very severe airflow obstruction (forced expiratory volume in one second (FEV1) $0.74 \pm 0.17$ vs $0.91 \pm 0.19 \mathrm{~L}$, during exacerbation and stable conditions, respectively; $p=0.01$ ), severe hypoxaemia (ratio between arterial oxygen tension and inspired oxygen fraction $\left(\mathrm{P}_{\mathrm{a}}, \mathrm{O}_{2} / \mathrm{FI}, \mathrm{O}_{2}\right) 32.7 \pm 7.7$ vs $37.6 \pm 6.9 \mathrm{kPa}(245 \pm 58$ vs $282 \pm 52 \mathrm{mmHg}) ; \mathrm{p}=0.01)$ and hypercapnia (arterial carbon dioxide tension $\left(\mathrm{P}_{\left.\mathrm{a}, \mathrm{CO}_{2}\right)} 6.8 \pm 1.6\right.$ vs $5.9 \pm 0.8 \mathrm{kPa}(51 \pm 12$ vs $\left.44 \pm 6 \mathrm{mmHg}) ; \mathrm{p}=0.04\right)$. $V^{\prime} \mathrm{A} / Q$ ' inequality increased during exacerbation $\left(\log \mathrm{SD} Q Q^{\prime}, 1.10 \pm 0.29 v s 0.96 \pm 0.27\right.$; normal $\leq 0.6 ; \mathbf{p}=0.04$ ) as a result of greater perfusion in poorly-ventilated alveoli. Shunt was almost negligible on both measurements. $V^{\prime} \mathrm{E}$ remained essentially unchanged during exacerbation $\left(10.5 \pm 2.2\right.$ vs $\left.9.2 \pm 1.8 \mathrm{~L} \cdot \mathrm{min}^{-1} ; \mathrm{p}=0.1\right)$, whereas both $\bar{Q}^{\prime}\left(6.1 \pm 2.4\right.$ vs $\left.5.1 \pm 1.7 \mathrm{~L} \cdot \mathrm{min}^{-1} ; \mathrm{p}=0.05\right)$ and $V^{\prime} \mathrm{O}_{2}\left(300 \pm 49\right.$ vs $\left.248 \pm 59 \mathrm{~mL} \cdot \mathrm{min}^{-1} ; \mathrm{p}=0.03\right)$ increased significantly. Worsening of hypoxaemia was explained mainly by the increase both in $V^{\prime} \mathrm{A} / Q^{\prime}$ inequality and $V^{\prime} \mathrm{O}_{2}$, whereas the increase in $\bar{Q}$ ' partially counterbalanced the effect of greater $V^{\prime} \mathrm{O}_{2}$ on mixed venous oxygen tension $\left(P_{\bar{v}}, O_{2}\right)$.

We conclude that worsening of gas exchange during exacerbations of chronic obstructive pulmonary disease is primarily produced by increased ventilation/perfusion inequality, and that this effect is amplified by the decrease of mixed venous oxygen tension that results from greater oxygen consumption, presumably because of increased work of the respiratory muscles.

Eur Respir J 1997; 10: 1285-1291.
Servei de Pneumologia i Al.lèrgia Respiratòria, Departament de Medicina, Hospital Clínic, Universitat de Barcelona, Spain. *Present address, Departamento de Enfermedades Respiratorias, Pontificia Universidad de Chile, Chile.

Correspondence: J.A. Barberà

Servei de Pneumologia i Al.lèrgia Respiratòrio

Hospital Clínic

Villarroel 170

08036 Barcelona

Spain

Keywords: Oxygen consumption respiratory insufficiency ventilation/perfusion relationships

Received: August 271996

Accepted after revision February 251997

Supported by Grants 89/0698 and 95/0544 from the Fondo de Investigaciones Sanitarias (FIS), and 1996 SGR-00122 from the Comissionat per a Universitats i Recerca (Generalitat de Catalunya).
Episodes of acute exacerbation are one of the most common complications in the evolution of chronic obstructive pulmonary disease (COPD). Irrespective of the precipitating factor, these episodes are characterized by worsening of pulmonary gas exchange that results in severe hypoxaemia with or without hypercapnia [1]. Abnormal gas exchange is thought to have a multifactorial origin [2], although some evidence suggests greater ventilation/perfusion $\left(V^{\prime} \mathrm{A} / Q^{\prime}\right)$ inequality as the major determinant of respiratory failure $[3,4]$. However, little information exists concerning the characteristics of the $V^{\prime} \mathrm{A} / Q^{\prime}$ distributions and their interrelations with the conditions under which the lung operates, namely the extrapulmonary factors (i.e. ventilation, cardiac output, oxygen uptake) that also influence the arterial blood gas values. This lack of information is due essentially to the difficulty of assessing and quantifying the degree of $V^{\prime} \mathrm{A} / Q^{\prime}$ mismatch. In this regard, the use of the multiple inert gas elimination technique has been a major advance in interpreting gas exchange abnormalities, as it allows quantitation of $V^{\prime} \mathrm{A} / Q^{\prime}$ distributions and characterization of the different factors that produce hypoxaemia [5]. Identification and interpretation of the pathophysiological determinants of abnormal gas exchange during exacerbations of COPD should help to optimize the management of such episodes [6, 7].

Accordingly, the present study was undertaken to investigate the contribution of the different mechanisms that determine abnormal gas exchange during acute exacerbations of COPD by using the inert gas elimination technique, and to examine how the factors contributing to abnormal gas exchange vary during recovery. 


\section{Materials and methods}

\section{Subjects}

We studied 13 male patients, mean ( \pm SD) age $62 \pm 7$ yrs, who fulfilled the criteria for the diagnosis of COPD $[6,7]$ and were admitted to hospital because of an acute exacerbation of their disease. Pulmonary function tests performed during stable periods showed severe airflow obstruction (forced expiratory volume in one second (FEV1) $29 \pm 6 \%$ of predicted), moderately increased total lung capacity (TLC) $(119 \pm 14 \%$ pred), and moderateto-severe reduction of carbon monoxide transfer factor ( $57 \pm 23 \%$ pred). On admission to the emergency room, patients showed severe hypoxaemia (arterial oxygen tension $\left.\left(\mathrm{Pa}, \mathrm{O}_{2}\right) 5.9 \pm 1.7 \mathrm{kPa}(44 \pm 11 \mathrm{mmHg})\right)$, hypercapnia (arterial carbon dioxide tension $\left(P \mathrm{a}, \mathrm{CO}_{2}\right) 7.3 \pm 1.2 \mathrm{kPa}$ $(55 \pm 9 \mathrm{mmHg}))$, and low arterial $\mathrm{pH}(7.35 \pm 0.08)$. The decision to admit a patient to hospital was made by the attending physicians. In all cases, the exacerbation was attributed to nonspecific bronchial infection without evidence of atelectasis or consolidation on chest radiography. Furthermore, patients in whom there was a suspicion of pulmonary thromboembolism or left heart failure, as well as those who required mechanical ventilation, were excluded from the study. All patients received standard treatment with supplemental oxygen, inhaled bronchodilators (salbutamol and ipratropium bromide) and intravenous corticosteroids. As decided by the housestaff of the ward, some patients were additionally treated with intravenous aminophylline, antibiotics and/or diuretics. The study was approved by the Ethics Committee of Hospital Clínic, and written informed consent was obtained from each participant.

\section{Procedures}

Triplicate measurements of FEV1 and forced vital capacity (FVC) were performed (Datospir 2002; Sibel, Barcelona, Spain) according to the recommendations of the European Respiratory Society [8]. Predicted equations were those of our own laboratory [9].

Blood samples for inert gas measurements were collected through a small Teflon catheter inserted into the radial artery or a peripheral vein. Arterial $\mathrm{pH}, \mathrm{Pa}_{\mathrm{a}} \mathrm{O}_{2}$ and $P \mathrm{a}, \mathrm{CO}_{2}$ were analysed using standard electrodes (IL 1302; Instrumentation Laboratories, Milan, Italy). Haemoglobin concentration was measured with a co-oximeter (IL 482; Instrumentation Laboratories, Milan, Italy). A central venous catheter was used to inject indocyanine green dye to measure the cardiac output by the dye dilution method (Waters Instruments Inc., Rochester, NY, USA). A low dead space, low resistance, non-rebreathing valve (model 1500; Hans Rudolph Instruments, Kansas City, MO, USA) connected to a heated metal mixing chamber was used to collect mixed expired gas. Respiratory frequency $(f \mathrm{R})$ and minute ventilation $\left(V^{\prime} \mathrm{E}\right)$ were measured using a calibrated Wright respirometer (Respirometer MK8; BOC-Medical, Essex, UK). Oxygen uptake $\left(V^{\prime} \mathrm{O}_{2}\right)$ and carbon dioxide production $\left(V^{\prime} \mathrm{CO}_{2}\right)$ were computed from mixed expired oxygen and carbon dioxide concentrations measured by mass spectrometry (Multigas MS2; Ohmeda BOC, UK). The alveolar-arterial oxygen gra- dient $\left(P(\mathrm{~A}-\mathrm{a}) \mathrm{O}_{2}\right)$ was calculated according to the standard alveolar gas equation using the measured respiratory exchange ratio.

Ventilation/perfusion distributions were estimated by using the multiple inert gas elimination technique [5]. The position, both of perfusion and ventilation distributions, was described by the $V^{\prime} \mathrm{A} / Q^{\prime}$ ratio at their mean, and their dispersions on a logarithmic scale $\left(\log \mathrm{SD} Q^{\prime}\right.$ and $\log$ SD $V^{\prime}$, respectively) were used as indices of $V^{\prime} \mathrm{A} / Q^{\prime}$ inequality. The upper $95 \%$ confidence limit (95\% CL) for $\log \mathrm{SD} Q^{\prime}$ is 0.60 , and for $\log \mathrm{SD} V^{\prime}$ is 0.65 [5]. As an overall descriptor of the combined dispersions both of blood flow and ventilation distributions, we used the differences among measured retentions and excretions of the inert gases corrected for the excretion of acetone (DISP R-E*; normal value $\leq 3.0$ ), which also includes intrapulmonary shunt when this is present [10]. Intrapulmonary shunt was defined as the fraction of cardiac output perfusing lung units with $V^{\prime} \mathrm{A} / Q^{\prime}$ ratios lower than 0.005 , and dead space as the ventilation to units with $V^{\prime} \mathrm{A} / Q^{\prime}$ ratios greater than 100 .

\section{Study design and measurements}

Patients were studied $18 \pm 5 \mathrm{~h}$ after admission, when they were able to breathe through the breathing circuit, and $38 \pm 10$ days after hospital discharge, once they were in a stable clinical condition. Medication as decided by the attending physician was kept unmodified. All patients were afebrile on the day of study. At the initial evaluation, eight patients were breathing room air and five were receiving supplemental oxygen, at an inspired oxygen fraction $\left(F \mathrm{I}, \mathrm{O}_{2}\right)$ of $26 \pm 2 \%$ (range $\left.22-27 \%\right)$. In the study performed after hospital discharge, all but one of the patients were breathing room air. To overcome the effect of a different $F \mathrm{I}_{1} \mathrm{O}_{2}$ on the $\mathrm{Pa}, \mathrm{O}_{2}$ value, arterial oxygenation was expressed by means of the $\mathrm{Pa}, \mathrm{O}_{2} / F \mathrm{I}, \mathrm{O}_{2}$ ratio. All studies were performed at the same time of the day (between 10.00 and $12.00 \mathrm{~h}$ ), $4 \mathrm{~h}$ after the administration of inhaled bronchodilators. Steady state during measurements was assessed by the stability (within $\pm 5 \%$ ) of cardiac frequency $(f \mathrm{C})$, arterial pressure, $f \mathrm{R}$ and $V^{\prime} \mathrm{E}$, as well as by agreement of inert gas data between duplicate samples.

In 10 patients, two additional measurements were performed during their hospital stay, at day $6 \pm 1$ after admission and at discharge (day 15 \pm 13 ), thus allowing more detailed evaluation of the sequential evolution of gas exchange alterations. These additional measurements were performed without arterial catheterization; blood for inert gas analysis being sampled from a peripheral vein [11], and that for the measurement of respiratory gas values by arterial puncture. The former inert gas approach provides an accurate assessment of $V^{\prime} \mathrm{A} / Q^{\prime}$ distributions with minimal constraints [11].

To evaluate the relative contributions of the different factors that determine hypoxaemia, we computed the $P \mathrm{a}, \mathrm{O}_{2}$ expected to result from the measured $V^{\prime} \mathrm{A} / Q^{\prime}$ inequality and a particular combination of extrapulmonary factors (overall ventilation, cardiac output $\left(\bar{Q}^{\prime}\right)$ and $\left.V^{\prime} \mathrm{O}_{2}\right)$ using the algorithm described by WEST and WAGNER [12]. For this purpose, we changed in turn each extrapulmonary or intrapulmonary $\left(V^{\prime} \mathrm{A} / Q^{\prime}\right.$ distribution) 
factor at the level corresponding to the acute exacerbation, keeping the remaining factors at the values measured under stable conditions. These theoretical calculations were carried out with data from seven patients, on whom the full set of measurements (including $\bar{Q}^{\prime}$ and $\left.V^{\prime} \mathrm{O}_{2}\right)[5,12]$ was obtained both during exacerbation and under stable conditions.

Table 1. - Spirometric and gas exchange data during acute exacerbation and stable clinical conditions

\begin{tabular}{|c|c|c|c|}
\hline & $\begin{array}{c}\text { Acute } \\
\text { exacerbation }\end{array}$ & $\begin{array}{c}\text { Stable } \\
\text { conditions }\end{array}$ & p-value \\
\hline FEV1 L & $0.74 \pm 0.17$ & $0.91 \pm 0.19$ & 0.01 \\
\hline FVC L & $2.17 \pm 0.53$ & $2.70 \pm 0.55$ & 0.004 \\
\hline $\mathrm{FEV}_{1 / \mathrm{FVC}} \%$ & $36 \pm 10$ & $35 \pm 10$ & 0.77 \\
\hline$P \mathrm{a}, \mathrm{O}_{2} / F \mathrm{I}, \mathrm{O}_{2} \mathrm{kPa}$ & $32 \pm 7.7$ & $37.6 \pm 6.9$ & 0.01 \\
\hline $\begin{array}{ll} & \mathrm{mmHg} \\
\mathrm{P}_{\mathrm{a}, \mathrm{CO}_{2}} & \mathrm{kPa} \\
& \mathrm{mmHg}\end{array}$ & $\begin{array}{c}245 \pm 58 \\
6.8 \pm 1.6 \\
51 \pm 12\end{array}$ & $\begin{array}{c}282 \pm 52 \\
5.9 \pm 0.8 \\
44 \pm 6\end{array}$ & 0.04 \\
\hline$V^{\prime} \mathrm{E} \mathrm{L} \cdot \mathrm{min}^{-1}$ & $10.5 \pm 2.2$ & $9.2 \pm 1.8$ & 0.10 \\
\hline $\bar{Q}^{\prime} \mathrm{L} \cdot \mathrm{min}^{-1 \dagger}$ & $6.1 \pm 2.4$ & $5.1 \pm 1.7$ & 0.05 \\
\hline$V^{\prime} \mathrm{O}_{2} \mathrm{~mL} \cdot \mathrm{min}^{-1 \ddagger}$ & $300 \pm 49$ & $248 \pm 59$ & 0.03 \\
\hline $\mathrm{Hb} \mathrm{mg} \cdot \mathrm{dL}^{-1}$ & $13.9 \pm 2.1$ & $14.0 \pm 2.2$ & 0.97 \\
\hline Shunt $\% \bar{Q}^{\prime}$ & $1.8 \pm 1.8$ & $1.3 \pm 1.7$ & 0.37 \\
\hline Low $V^{\prime} \mathrm{A} / Q^{\prime} \% \bar{Q}^{\prime}$ & $9.2 \pm 12.9$ & $4.1 \pm 8.6$ & 0.07 \\
\hline $\log \operatorname{SD} Q^{\prime}$ & $1.10 \pm 0.29$ & $0.96 \pm 0.27$ & 0.04 \\
\hline $\log \operatorname{SD} V^{\prime}$ & $1.24 \pm 0.38$ & $1.08 \pm 0.30$ & 0.22 \\
\hline High $V^{\prime} \mathrm{A} / \mathrm{Q}^{\prime} \quad \% V^{\prime} \mathrm{E}$ & $8.3 \pm 8.5$ & $4.0 \pm 5.1$ & 0.07 \\
\hline Dead space $\% V^{\prime} \mathrm{E}$ & $41 \pm 7$ & $43 \pm 9$ & 0.48 \\
\hline DISP R-E* & $17.8 \pm 5.7$ & $13.7 \pm 3.8$ & 0.01 \\
\hline
\end{tabular}

Values are presented as mean \pm SD. $\dagger: n=10$; $\ddagger$ : $=11$. FEV1: forced expiratory volume in one second; FVC: forced vital capacity. $P \mathrm{a}_{2} \mathrm{O}_{2} / F \mathrm{I}, \mathrm{O}_{2}$ : ratio between arterial oxygen tension and inspired oxygen fraction; $P \mathrm{a}_{1} \mathrm{CO}_{2}$ : arterial carbon dioxide tension; $V^{\prime} \mathrm{E}$ : minute ventilation; $\bar{Q}^{\prime}$ : cardiac output; $V^{\prime} \mathrm{O}_{2}$ : oxygen consumption; $\mathrm{Hb}$ : haemoglobin; shunt: perfusion to alveolar units with $V^{\prime} \mathrm{A} / Q^{\prime}$ ratios $<0.005$; low $V^{\prime} \mathrm{A} / Q^{\prime}$ : perfusion to alveolar units with $V^{\prime} \mathrm{A} / Q^{\prime}$ ratios between 0.005 and 0.1 ; $\log \operatorname{SD} Q^{\prime}$ : dispersion of blood flow distribution; $\log$ SD $V^{\prime}$ : dispersion of ventilation distribution; high $V^{\prime} \mathrm{A} / Q^{\prime}$ : ventilation to units with $V^{\prime} \mathrm{A} / Q^{\prime}$ ratio between 10 and 100 ; dead space: ventilation to units with $V^{\prime} \mathrm{A} / Q^{\prime}$ ratios $>100$; DISP R-E*: dispersion of retention minus excretion of inert gases corrected by dead space.

\section{Statistical analysis}

Data are expressed throughout as mean \pm sD. Differences between exacerbations and stable conditions were analysed using Student's t-test for paired data. Results of the sequential evolution studies were analysed using a repeated measures analysis of variance (ANOVA). When significant differences were detected, comparisons with the initial study were performed using paired t-tests. Probability values less than 0.05 were considered statistically significant.

\section{Results}

\section{Gas exchange abnormalities during exacerbation}

At the initial evaluation performed within the first 24 $\mathrm{h}$ after admission, gas exchange was markedly abnormal (table 1). Mean $\mathrm{Pa}, \mathrm{O}_{2}$ of the eight patients who were breathing room air was $7.1 \pm 1.6 \mathrm{kPa}(53 \pm 12 \mathrm{mmHg})$, and for the whole population $P \mathrm{a}, \mathrm{O}_{2} / F \mathrm{I}, \mathrm{O}_{2}$ was $32.7 \pm 7.7$ $\mathrm{kPa}(245 \pm 58 \mathrm{mmHg})$. These values were significantly lower than those shown under stable conditions, when $P \mathrm{a}_{1} \mathrm{O}_{2}$ of patients breathing room air was $8.0 \pm 1.5 \mathrm{kPa}$ $(60 \pm 11 \mathrm{mmHg})$, and $P \mathrm{a}_{1} \mathrm{O}_{2} / F \mathrm{I}, \mathrm{O}_{2}$ of all subjects was $37.6 \pm$ $6.9 \mathrm{kPa}(282 \pm 52 \mathrm{mmHg})(\mathrm{p}=0.01$ compared with exacerbation) (fig. 1). In the assessment performed during the exacerbation, eight patients showed hypercapnia, whereas only four patients remained hypercapnic once they were clinically stable. Overall, $P \mathrm{a}, \mathrm{CO}_{2}$ was $0.9 \pm 1.3$ $\mathrm{kPa}(7 \pm 10 \mathrm{mmHg})$ higher during exacerbation (table 1$)$. Arterial $\mathrm{pH}$ was within normal limits in most subjects during both studies $(7.391 \pm 0.040$ and $7.387 \pm 0.044$, during exacerbation and stable conditions, respectively; $\mathrm{p}=0.78) . P \mathrm{a}, \mathrm{CO}_{2}$ and $\mathrm{pH}$ values at the initial assessment were somewhat different from those obtained in the emergency room (see Materials and methods), probably as a result of the intensive treatment administered during the first hours of hospitalization, and also because the initial measurements were conducted once the patients were able to breathe through the respiratory circuit.
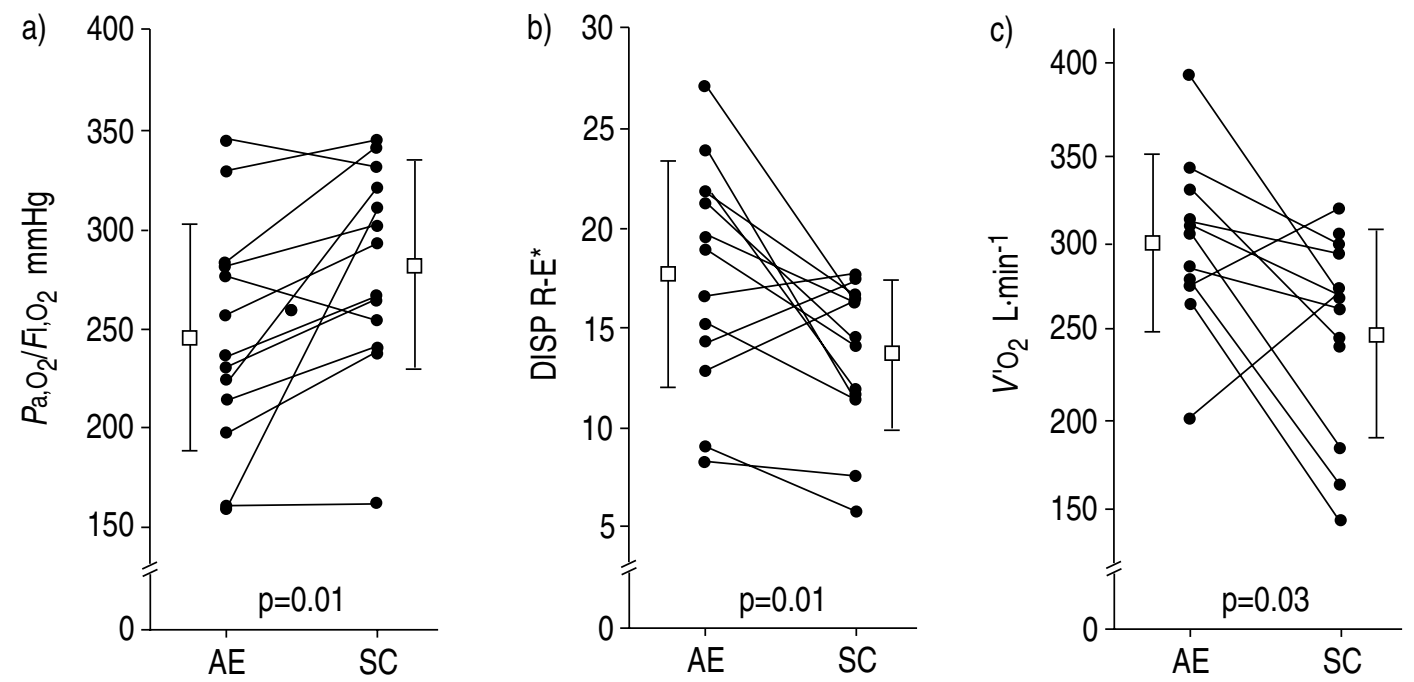

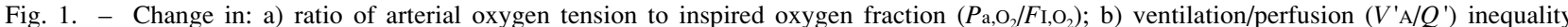
(expressed as the dispersion of retention minus excretion of inert gases corrected by dead space (DISP R-E*)); and c) oxygen consumption $\left(V^{\prime} \mathrm{O}_{2}\right)$, from acute exacerbation (AE) to stable conditions (SC). Open symbols and vertical bars denote mean $\pm \mathrm{SD} .1 \mathrm{mmHg}=0.133 \mathrm{kPa}$. 
During exacerbations, all patients had moderate-tosevere $V^{\prime} \mathrm{A} / Q^{\prime}$ inequality, as shown by an increased dispersion both of blood flow (log SD $\left.Q^{\prime}, 1.10 \pm 0.29\right)$ and ventilation $\left(\log \mathrm{SD} V^{\prime}, 1.24 \pm 0.38\right)$ distributions (normal $\leq 0.60$ and $\leq 0.65$, respectively). The overall index of $V^{\prime} \mathrm{A} / Q^{\prime}$ inequality (DISP R-E* $17.8 \pm 5.7$ ) was also substantially increased (normal $\leq 3.0$ ). Compared with stable conditions, there was greater $V^{\prime} \mathrm{A} / Q^{\prime}$ inequality during the exacerbation (table 1 and fig. 1). Such an increase in $V^{\prime} \mathrm{A} / Q^{\prime}$ inequality was essentially due to greater perfusion in poorly-ventilated lung units, with $V^{\prime} \mathrm{A} / Q^{\prime}$ ratios lower than 0.1 (excluding shunt) (table 1), the latter also being reflected in a higher dispersion of blood flow distribution $\left(\log \mathrm{SD} Q^{\prime}\right)$. Intrapulmonary shunt was almost negligible on both measurements (table 1). Both dead space and the dispersion of ventilation distribution $\left(\log \mathrm{SD} V^{\prime}\right)$ during exacerbations did not differ significantly from the values shown when patients were clinically stable (table 1).

$V^{\prime}$ E was moderately increased during exacerbations (table 1$)$, essentially as result of a high $f \mathrm{R}(21 \pm 7$ breaths. $\left.\min ^{-1}\right)$, whereas tidal volume $(V \mathrm{~T})$ was within the normal range $(526 \pm 154 \mathrm{~mL})$. During exacerbations, $\bar{Q}^{\prime}$ was normal or slightly increased (table 1 ) and the $f \mathrm{C}$ was moderately high $\left(88 \pm 15\right.$ beats $\left.\cdot \mathrm{min}^{-1}\right)$. Compared with stable conditions, $V^{\prime} \mathrm{E}$ and the breathing pattern remained essentially unchanged, whereas both $\bar{Q}^{\prime}$ and $V^{\prime} \mathrm{O}_{2}$ were significantly higher (table 1 ).

Figure 2 shows the relative contributions of the changes in the latter parameters to arterial oxygenation. Whereas the minimal increase in $V^{\prime} \mathrm{E}$ did not alter the $\mathrm{Pa}, \mathrm{O}_{2} /$ $F \mathrm{I}, \mathrm{O}_{2}$ ratio, increases in $\bar{Q}^{\prime}$ and $V^{\prime} \mathrm{O}_{2}$ exerted significant but opposite effects on oxygenation. Thus, whilst the increase in $\bar{Q}^{\prime}$ alone would have raised $\mathrm{Pa}_{\mathrm{a}} \mathrm{O}_{2} / F \mathrm{I}, \mathrm{O}_{2}$ by 8.0 $\mathrm{kPa}(60 \mathrm{mmHg})$, the increase in $V^{\prime} \mathrm{O}_{2}$ alone would have

\section{현 Ventilation \\ Cardiac output \\ $\mathrm{O}_{2}$ consumption \\ Extrapulmonary factors $\left(V^{\prime} \mathrm{E}, Q^{\prime}, V^{\prime} \mathrm{O}_{2}\right.$ combined) \\ $V^{\prime} \mathrm{A} / Q$ ' inequality}

Actual measurement during exacerbation

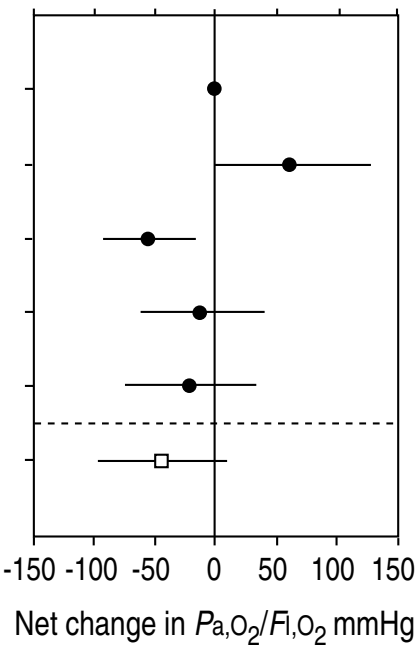

Fig. 2. - Analysis of the relative contributions of the factors that determined the change in ratio of arterial oxygen tension to inspired oxygen fraction $\left(\mathrm{Pa}_{\mathrm{a}} \mathrm{O}_{2} / F_{\mathrm{I}}, \mathrm{O}_{2}\right)$ during an acute exacerbation of chronic obstructive pulmonary disease (COPD). Values are the mean difference in $\mathrm{Pa}_{\mathrm{a}} \mathrm{O}_{2} / \mathrm{F}_{\mathrm{I}} \mathrm{O}_{2}$ measured under stable clinical conditions minus that predicted to result from a specific change, at the level corresponding to the exacerbation, in: minute ventilation $\left(V^{\prime} \mathrm{E}\right)$, cardiac output $\left(\bar{Q}^{\prime}\right)$, oxygen consumption $\left(V^{\prime} \mathrm{O}_{2}\right)$ and ventilation/perfusion $\left(V^{\prime} \mathrm{A} / Q^{\prime}\right)$ inequality (closed symbols). The open symbol shows the actual change in $\mathrm{Pa}_{\mathrm{a}} \mathrm{O}_{2} / \mathrm{F}_{\mathrm{I}} \mathrm{O}_{2}$ during exacerbation. Lines indicate the $95 \%$ confidence intervals. Data from seven patients are shown. $1 \mathrm{mmHg}=0.133$ $\mathrm{kPa}$. decreased it by $7.5 \mathrm{kPa}(56 \mathrm{mmHg})$. Taken together, the combined changes in $V^{\prime} \mathrm{E}, \bar{Q}^{\prime}$, and $V^{\prime} \mathrm{O}_{2}$ would have reduced $\mathrm{Pa}_{\mathrm{a}, \mathrm{O}_{2}} / \mathrm{FI}_{\mathrm{I}} \mathrm{O}_{2}$ by $1.7 \mathrm{kPa}(13 \mathrm{mmHg})$. Furthermore, if the only change during exacerbation had been the increase in $V^{\prime} \mathrm{A} / Q^{\prime}$ inequality, $P \mathrm{a}, \mathrm{O}_{2} / F \mathrm{I}, \mathrm{O}_{2}$ would have

a)
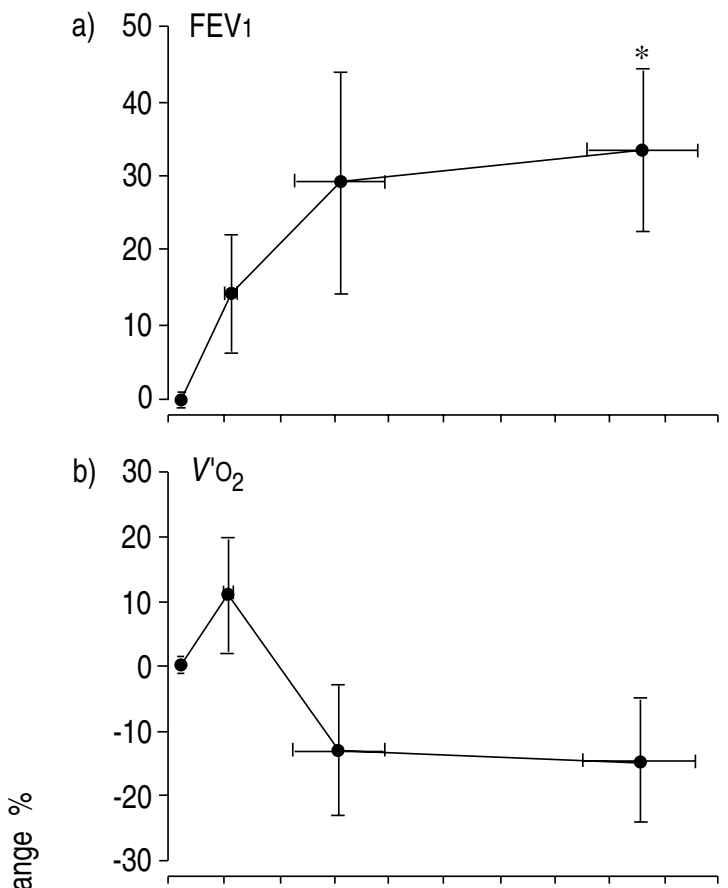

c) $40_{7} \mathrm{~Pa}, \mathrm{O}_{2} / \mathrm{Fl}, \mathrm{O}_{2}$

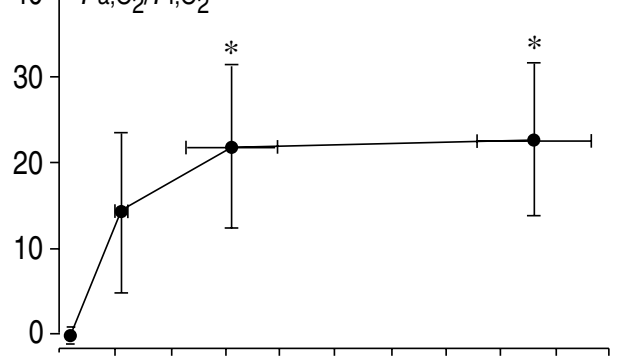

d)

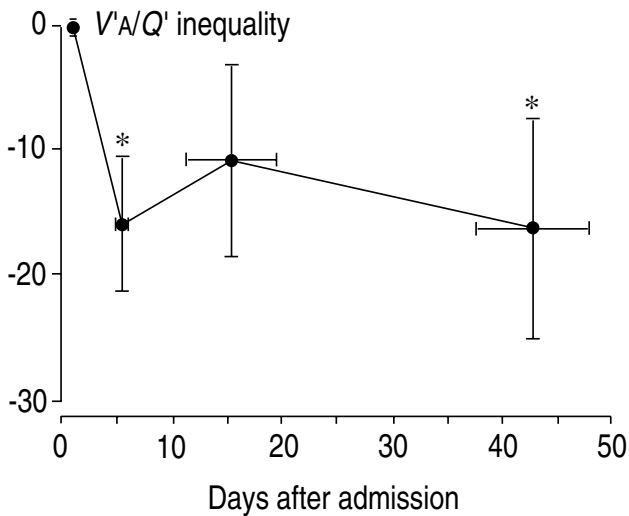

Fig. 3. - Sequential evolution of spirometric and gas exchange measurements during hospitalization and after discharge (day $15 \pm 4$ ). Values are the mean ( \pm SEM) percentage change from the value obtained at the initial study of: a) forced expiratory volume in one second (FEV1); b) oxygen consumption $\left(V^{\prime} \mathrm{O}_{2}\right)$; c) ratio of arterial oxygen tension to inspired oxygen fraction $\left(\mathrm{Pa}_{\mathrm{a}} \mathrm{O}_{2} / F_{\mathrm{I}}, \mathrm{O}_{2}\right)$; and $\left.\mathrm{d}\right)$ ventilation/perfusion $\left(V^{\prime} \mathrm{A} / Q^{\prime}\right)$ inequality (expressed as DISP R-E*). The asterisks indicate significant differences $(\mathrm{p}<0.05)$ compared with values at the initial assessment. Data from 10 patients are shown. 
decreased by $2.8 \mathrm{kPa}(21 \mathrm{mmHg})$. The actual decrease of $\mathrm{Pa}, \mathrm{O}_{2} / F \mathrm{I}, \mathrm{O}_{2}$ in this particular subgroup of patients $(\mathrm{n}=7)$ during the exacerbation was $6.0 \mathrm{kPa}(45 \mathrm{mmHg})$. Accordingly, we estimate that $28 \%$ of the $\mathrm{Pa}, \mathrm{O}_{2} \mathrm{FI}_{\mathrm{I}} \mathrm{O}_{2}$ reduction can be attributed to the combined change of $V^{\prime} \mathrm{O}_{2}$ and $\bar{Q}^{\prime}$, whereas the worsening of $V^{\prime} \mathrm{A} / Q^{\prime}$ inequality alone may account for $46 \%$ of such a reduction. Since a decrease in mixed venous oxygen tension $\left(P \bar{v}, \mathrm{O}_{2}\right)$ amplifies the effect of $V^{\prime} \mathrm{A} / Q^{\prime}$ inequality on arterial oxygenation, the effect of these changes occurring together during the exacerbation explains the remaining $26 \%$ of the reduction in $\mathrm{Pa}, \mathrm{O}_{2} / F \mathrm{I}, \mathrm{O}_{2}$.

\section{Spirometric changes during exacerbation}

Forced spirometry disclosed a very severe degree of airflow obstruction during exacerbation, as shown by markedly low FEV1 $(23 \pm 5 \%$ of predicted $)$ and FVC (48 $\pm 12 \%$ pred) (table 1). Compared with stable conditions, FEV1 was significantly lower during exacerbation. Since FVC was also reduced, the FEV1/FVC ratio was unchanged.

\section{Sequential evolution from exacerbation to recovery}

The time course of spirometric and gas exchange measurements during the hospitalization period in patients who underwent the full follow-up study (including four time-points) are shown in figure 3. FEV1 increased progressively during hospitalization, and at discharge $(129 \pm 44 \%$ of the first measurement) almost reached the value observed under stable conditions $(133 \pm 32 \%$ of the first measurement). A similar trend was shown for gas exchange variables. The $\mathrm{Pa}, \mathrm{O}_{2} / F \mathrm{I}, \mathrm{O}_{2}$ ratio increased significantly at the end of the hospitalization period (122士 $30 \%$ of the first measurement), whereas ventilation/perfusion distributions (DISP R-E*) reached their maximal improvement at the second time-point $(84 \pm 28 \%$ of the first measurement), performed 6 days after admission, and did not change significantly thereafter. Finally, $V^{\prime} \mathrm{O}_{2}$, which was already moderately elevated at the initial assessment, increased further at the second assessment (111 $\pm 26 \%$ of the first measurement), decreasing later on.

\section{Discussion}

The most striking findings of the present study were that worsening of pulmonary gas exchange during COPD exacerbations was produced primarily by an increase in $V^{\prime} \mathrm{A} / Q^{\prime}$ inequality, and that this effect was amplified by the decrease of $P \overline{\mathrm{v}}, \mathrm{O}_{2}$ that ensued from a greater $V^{\prime} \mathrm{O}_{2}$. The latter, however, was partially counterbalanced by an increased $\bar{Q}^{\prime}$.

As expected, deterioration of $V^{\prime} \mathrm{A} / Q^{\prime}$ relationships was the major determinant of respiratory failure during the exacerbation. Compared with stable clinical conditions, a greater proportion of blood flow was diverted through poorly-ventilated lung units with low $V^{\prime} \mathrm{A} / Q$ ' ratios. Possibly, this was the result of greater narrowing of the airways by inflammation of the wall, bronchospasm, or mucous secretions $[13,14]$. It is of note that intrapulmonary shunt, trivial under stable conditions, did not increase during the exacerbation, implying the absence of completely occluded airways and/or efficient collateral ventilation [15].

Our analysis suggests, however, that the increase in $V^{\prime} \mathrm{A} / Q^{\prime}$ inequality by itself did not completely explain the worsening of arterial oxygenation (fig. 2), and that other factors must have been present to reduce $P \mathrm{a}, \mathrm{O}_{2}$. Among these, the most influential was an increased $V^{\prime} \mathrm{O}_{2}$ (fig. 2). According to the Fick principle, if the oxygen consumption by the tissues increases, the oxygen concentration of mixed venous blood will decrease, provided other factors remain equal. As shown by Mithoefer et al. [16] in COPD patients, changes in $P \overline{\mathrm{v}}, \mathrm{O}_{2}$ play a critical role in arterial oxygenation. For a given degree of $V^{\prime} \mathrm{A} / Q^{\prime}$ inequality, the lower the $P \overline{\mathrm{v}}, \mathrm{O}_{2}$ the lower the $P \mathrm{a}, \mathrm{O}_{2}[17,18]$. We consider that in our patients the increased $V^{\prime} \mathrm{O}_{2}$ shown during exacerbations lowered the $P \overline{\mathrm{v}}, \mathrm{O}_{2}$. Indeed, $P \overline{\mathrm{v}}, \mathrm{O}_{2}$ calculated by mass balance [12] in seven patients of the series was reduced during exacerbation $(4.3 \pm 0.9 \mathrm{kPa}(32 \pm 7 \mathrm{mmHg}))$ compared with stable conditions $(4.9 \pm 0.7 \mathrm{kPa}(37 \pm 5 \mathrm{mmHg}))(\mathrm{p}=0.01)$. Such a decrease in $P \overline{\mathrm{v}}, \mathrm{O}_{2}$ would decrease $\mathrm{Pa}_{\mathrm{a}} \mathrm{O}_{2}$ by a direct effect and, more importantly, by amplifying the impact of increased $V^{\prime} \mathrm{A} / Q^{\prime}$ inequality on end-capillary oxygen tension [18].

It is of note that the adverse effect of greater $V^{\prime} \mathrm{O}_{2}$ was partially counterbalanced by an increase in $\bar{Q}^{\prime}$, which tends to augment the oxygen concentration of mixed venous blood, without altering the degree of $V^{\prime} \mathrm{A} / Q^{\prime}$ inequality. However, such an increase in $\bar{Q}^{\prime}$ did not completely offset the effect of $V^{\prime} \mathrm{O}_{2}$ on $\mathrm{Pa}_{\mathrm{a}} \mathrm{O}_{2}$, since the estimated net effect of both changes occurring together was still a reduction of $P \mathrm{a}, \mathrm{O}_{2} / F \mathrm{I}, \mathrm{O}_{2}$ (fig. 2). This emphasizes that $\bar{Q}^{\prime}$ may play a critical role in modulating gas exchange during COPD exacerbations. Therefore, treatments that may reduce cardiac performance (diuretics, fluid restriction, negative inotropic agents) should be administered with caution as they may be inappropriate for optimal gas exchange.

$V^{\prime}$ 'E did not decrease during exacerbation. Instead, a slight increase was shown when compared with stable conditions (table 1). This finding reinforces the concept that the development of hypercapnia during exacerbations of COPD is essentially due to increased $V^{\prime} \mathrm{A} / Q^{\prime}$ inequality rather than hypoventilation $[19,20]$, at least in patients who were able to overcome the exacerbation episode without requiring mechanical ventilatory support.

The increase in $V^{\prime} \mathrm{O}_{2}$ during exacerbations may potentially be related to several factors, namely: the increased work of the respiratory muscles; treatment with $\beta_{2}$-agonists [21]; or a greater metabolic rate. We hypothesize that the most likely explanation was a greater energy expenditure by the stressed respiratory muscles. In COPD, the work and the energy cost of breathing is high because of an increased airway resistance and the effect of lung hyperinflation on inspiratory muscles [22], accounting for a significant proportion of the total body $V^{\prime} \mathrm{O}_{2}[23,24]$. During exacerbations, the oxygen demands of the respiratory muscles increase considerably due to greater airway resistance and to the additional efforts of inspiratory muscles to overcome dynamic 
hyperinflation [25], and may contribute to an augmented whole body $V^{\prime} \mathrm{O}_{2}$ that results in a lower $P \overline{\mathrm{v}}, \mathrm{O}_{2} . V^{\prime} \mathrm{O}_{2}$ increased further at the second assessment (day 6 ) of the time course evaluation despite improvements in airway function and $V^{\prime} \mathrm{A} / Q^{\prime}$ distributions (fig. 3). We hypothesize that this was probably due to the effects on the metabolic rate of intense treatment with $\beta$-agonists, as shown by AmOroso et al. [21]. Moreover, such an increase in $V^{\prime} \mathrm{O}_{2}$ could be the reason why the improvement in $V^{\prime} \mathrm{A} / Q^{\prime}$ distributions did not result in a further increase in $\mathrm{Pa}_{\mathrm{a}} \mathrm{O}_{2} / \mathrm{FI}_{\mathrm{I}} \mathrm{O}_{2}$ (fig. 3). Indeed, only when both $V^{\prime} \mathrm{O}_{2}$ and $V^{\prime} \mathrm{A} / Q^{\prime}$ inequality improved together at discharge was $\mathrm{Pa}, \mathrm{O}_{2} / F \mathrm{I}, \mathrm{O}_{2}$ increased significantly (fig. 3).

Five patients were studied during exacerbation while breathing supplemental oxygen. Accordingly, it could be argued that oxygen administration could potentially have modified $V^{\prime} \mathrm{A} / Q^{\prime}$ distributions as a result of the release of hypoxic pulmonary vasoconstriction. It has been shown that $100 \%$ oxygen breathing significantly increases $V^{\prime} \mathrm{A} / Q^{\prime}$ inequality in COPD patients $[3,26]$. However, it has also been shown that the administration of supplemental oxygen at concentrations of 28 and $40 \%$ does not modify $V^{\prime} \mathrm{A} / Q^{\prime}$ distributions [2]. Moreover, patients in the present series who were studied breathing room air also showed greater $V^{\prime} \mathrm{A} / Q^{\prime}$ inequality during exacerbation $(\mathrm{p}=0.08)$. Therefore, we suggest that the potential effect of supplemental oxygen breathing, at the concentrations used in this study, can be disregarded as a mechanism of worsening of $V^{\prime} \mathrm{A} / Q^{\prime}$ distributions during exacerbations.

The sequential evolution of the present data (fig. 3) shows that changes both in gas exchange and forced spirometry followed a parallel course. Thus, at the time of hospital discharge, patients had practically reached their maximum recovery in both functions. This is at variance with previous observations in patients hospitalized with an exacerbation of bronchial asthma, in whom gas exchange impairment was of greater magnitude than that observed in the present series and took longer to recover than forced spirometry [27, 28].

The finding that altered gas exchange during exacerbations of COPD results from increased $V^{\prime} \mathrm{A} / Q^{\prime}$ inequality together with a reduced oxygen content of mixed venous blood that results from greater consumption of oxygen by the respiratory muscles, suggests that improvement of these two factors should be of benefit for correction of hypoxaemia during exacerbations. Bronchodilators and anti-inflammatory agents may improve $V^{\prime} \mathrm{A} / Q^{\prime}$ relationships by reducing airway narrowing and dynamic hyperinflation, thereby increasing ventilation of alveoli with low $V^{\prime} \mathrm{A} / Q^{\prime}$ ratios. Furthermore, approaches addressed to reduce the demands on the respiratory muscles, either by reducing airway resistance or by providing mechanical support, may also be beneficial for improvement of gas exchange. Recent studies have shown that the use of noninvasive ventilation in exacerbations of COPD can improve gas exchange and reduce the need for endotracheal intubation $[29,30]$. The contention is that the recruitment of underventilated alveolar units by positive pressure ventilation should ameliorate gas exchange by increasing the alveolar ventilation [30]. Our findings also suggest that relief of the work performed by the respiratory muscles, thereby decreasing their energy demands, would contribute to raising the oxygen content of mixed venous blood and, hence, that of arterial blood. However, it should be considered that the application of mechanical ventilation may decrease the cardiac output [3], potentially neutralizing its beneficial role on gas exchange.

In summary, our results highlight the important role of extrapulmonary factors in modulating the impact of increased ventilation/perfusion inequality on arterial oxygenation. The complex interaction between oxygen consumption, cardiac output and ventilation/perfusion imbalance should be considered together, in order to optimize the treatment of acute exacerbations in patients with chronic obstructive pulmonary disease.

Acknowledgements: The authors thank the technical staff of the pulmonary function laboratory of the Hospital Clínic for their collaboration and P.D. Wagner for his comments.

\section{References}

1. Curtis JR, Hudson LD. Emergent assessment and management of acute respiratory failure in COPD. Clin Chest Med 1994; 15: 481-500.

2. Guénard H, Castaign Y, Mélot C, Naeije R. Gas exchange during acute respiratory failure in patients with chronic obstructive pulmonary disease. In: Derenne JP, Whitelaw WA, Smilowski TS, eds. Acute Respiratory Failure in Chronic Obstructive Pulmonary Disease. New York, Marcel Dekker, 1996; pp. 227-266.

3. Torres A, Reyes A, Roca J, Wagner PD, RodriguezRoisin R. Ventilation/perfusion mismatching in chronic obstructive pulmonary disease during ventilator weaning. Am Rev Respir Dis 1989; 140: 1246-1250.

4. Marthan R, Castaing Y, Manier G, Guénard H. Gas exchange alterations in patients with chronic obstructive lung disease. Chest 1985; 87: 470-475.

5. Roca J, Wagner PD. Contribution of multiple inert gas elimination technique to pulmonary medicine. 1. Principles and information content of the multiple inert gas elimination technique. Thorax 1994; 49: 815-824.

6. Siafakas NM, Vermeire P, Pride NB, et al. Optimal assessment and management of chronic obstructive pulmonary disease (COPD). Eur Respir J 1995; 8: 13981420.

7. American Thoracic Society. Standards for the diagnosis and care of patients with chronic obstructive pulmonary disease. Am J Respir Crit Care Med 1995; 152: S77-S120.

8. Quanjer PH, Tammeling GJ, Cotes JE, Pedersen OF, Peslin R, Yernault JC. Lung volumes and forced ventilatory flows. Report Working Party "Standardization of Lung Function Tests". Eur Respir J 1993; 6 (Suppl. 16): $5-40$.

9. Roca J, Sanchis J, Agustí-Vidal A, et al. Spirometric reference values for a Mediterranean population. Bull Eur Physiopathol Respir 1986; 22: 217-224.

10. Gale GE, Torre-Bueno JR, Moon RE, Saltzman HA, Wagner PD. Ventilation/perfusion inequality in normal humans during exercise at sea level and simulated altitude. J Appl Physiol 1985; 58: 978-988.

11. Wagner PD, Smith CM, Davies NJH, McEvoy RD, Gale GE. Estimation of ventilation/perfusion inequality by 
inert gas elimination without arterial sampling. $J$ Appl Physiol 1985; 59: 376-383.

12. West JB, Wagner PD. Pulmonary gas exchange. In: West JB, ed. Bioengineering Aspects of the Lung. New York, Marcel Dekker, 1977; pp. 361-457.

13. Bosken CH, Wiggs BR, Paré PD, Hogg JC. Small airway dimensions in smokers with obstruction to airflow. Am Rev Respir Dis 1990; 142: 563-570.

14. Kuwano K, Bosken CH, Paré PD, Bai TR, Wiggs BR, Hogg JC. Small airways dimensions in asthma and in chronic obstructive pulmonary disease. Am Rev Respir Dis 1993; 148: 1220-1225.

15. Rodriguez-Roisin R, Roca J. Pulmonary gas exchange. In: Calverley P, Pride N, eds. Chronic Obstructive Pulmonary Disease. London, Chapman \& Hall, 1995; pp. 161-184.

16. Mithoefer JC, Ramirez C, Cook W. The effect of mixed venous oxygenation on arterial blood in chronic obstructive pulmonary disease. Am Rev Respir Dis 1978; 117: 259-264.

17. West JB. Ventilation/perfusion relationships. Am Rev Respir Dis 1977; 116: 919-943.

18. Dantzker DR, Gutierrez G. Effects of circulatory failure on pulmonary and tissue gas exchange. In: Scharf SM, Cassidy SS, eds. Heart-lung interactions in health and disease. New York, Marcel Dekker, 1989; pp. 983-1019.

19. West JB. Causes of carbon dioxide retention in lung disease. N Engl J Med 1971; 284: 1232-1236.

20. Weinberger SE, Schwartzstein RM, Weiss JW. Hypercapnia. N Engl J Med 1989; 321: 1223-1231.

21. Amoroso P, Wilson SR, Moxham J, Ponte J. Acute effects of inhaled salbutamol on the metabolic rate of normal subjects. Thorax 1993; 48: 882-885.
22. Tobin MJ. Respiratory muscles in disease. Clin Chest Med 1988; 9: 263-286.

23. Field S, Kelly SM, Macklem PT. The oxygen cost of breathing in patients with cardiorespiratory disease. Am Rev Respir Dis 1982; 126: 9-13.

24. Jounieaux V, Mayeux I. Oxygen cost of breathing in patients with emphysema or chronic bronchitis in acute respiratory failure. Am J Respir Crit Care Med 1995; 152: 2181-2184.

25. Fleury B, Murciano D, Talamo C, Aubier M, Pariente R, Milic-Emili J. Work of breathing in patients with chronic obstructive pulmonary disease in acute respiratory failure. Am Rev Respir Dis 1985; 131: 822-827.

26. Barberà JA, Riverola $\mathrm{A}$, Roca $\mathrm{J}$, et al. Pulmonary vascular abnormalities and ventilation/perfusion relationships in mild chronic obstructive pulmonary disease. Am J Respir Crit Care Med 1994; 149: 423-429.

27. Roca J, Ramis L, Rodriguez-Roisin R, Ballester E, Montserrat JM, Wagner PD. Serial relationships between ventilation/perfusion inequality and spirometry in acute severe asthma requiring hospitalization. Am Rev Respir Dis 1988; 137: 1055-1061.

28. Ferrer A, Roca J, Wagner PD, López FA, RodriguezRoisin R. Airway obstruction and ventilation/perfusion relationships in acute severe asthma. Am Rev Respir Dis 1993; 147: 579-584.

29. Brochard L, Isabey D, Piquet J, et al. Reversal of acute exacerbations of chronic obstructive pulmonary disease by inspiratory assistance with a face mask. $N$ Engl J Med 1990; 323: 1523-1530.

30. Brochard L, Mancebo J, Wysocki M, et al. Noninvasive ventilation for acute exacerbations of chronic obstructive pulmonary disease. N Engl J Med 1995; 333: 817822. 